\title{
Biodegradation of lignin monomers and bioconversion of ferulic acid to vanillic acid by Paraburkholderia aromaticivorans AR20-38 isolated from Alpine forest soil
}

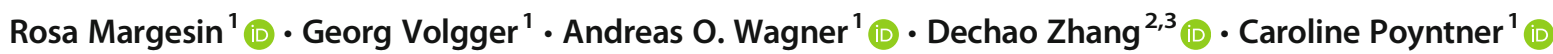

Received: 7 December 2020 / Revised: 10 February 2021 / Accepted: 28 February 2021 / Published online: 9 March 2021

(C) The Author(s) 2021

\begin{abstract}
Lignin bio-valorization is an emerging field of applied biotechnology and has not yet been studied at low temperatures. Paraburkholderia aromaticivorans AR20-38 was examined for its potential to degrade six selected lignin monomers (syringic acid, p-coumaric acid, 4-hydroxybenzoic acid, ferulic acid, vanillic acid, benzoic acid) from different upper funneling aromatic pathways. The strain degraded four of these compounds at $10^{\circ} \mathrm{C}, 20^{\circ} \mathrm{C}$, and $30^{\circ} \mathrm{C}$; syringic acid and vanillic acid were not utilized as sole carbon source. The degradation of $5 \mathrm{mM}$ and $10 \mathrm{mM}$ ferulic acid was accompanied by the stable accumulation of high amounts of the value-added product vanillic acid (85-89\% molar yield; 760 and $1540 \mathrm{mg}^{-1}$, respectively) over the whole temperature range tested. The presence of essential genes required for reactions in the upper funneling pathways was confirmed in the genome. This is the first report on biodegradation of lignin monomers and the stable vanillic acid production at low and moderate temperatures by $P$. aromaticivorans.
\end{abstract}

\section{Key points}

- Paraburkholderia aromaticivorans AR20-38 successfully degrades four lignin monomers.

- Successful degradation study at low $\left(10^{\circ} \mathrm{C}\right)$ and moderate temperatures $\left(20-30^{\circ} \mathrm{C}\right)$.

- Biotechnological value: high yield of vanillic acid produced from ferulic acid.

Keywords Lignin · Ferulic acid · Vanillic acid · Bioconversion · Cold-adapted ligninolytic Paraburkholderia

\section{Introduction}

Natural lignin is the second most abundant organic substance in the world (next to cellulose) (Ludmila et al. 2015; Ganewatta et al. 2019). The global amount of available lignin in the biosphere is approximately 300 billion tons, with an annual increase of approximately 20 billion tons (Becker and Wittmann 2019). It is found in the secondary cell wall of lignocellulosic plants and provides structural strength,

Rosa Margesin

rosa.margesin@uibk.ac.at

1 Institute of Microbiology, University of Innsbruck, Technikerstrasse 25, 6020 Innsbruck, Austria

2 Institute of Oceanology, Chinese Academy of Sciences, Qingdao 266071, China

3 University of Chinese Academy of Sciences, Beijing 100049, China impermeability, water transport in the cell wall, and protection from pathogens (Brink et al. 2019). Natural lignin is a complex aromatic heteropolymer and consists of a matrix of aromatic (phenolic) and aliphatic substances. Its complex threedimensional structure is a result of the polymerization of three phenylpropane units that originate from the three aromatic alcohols p-coumaryl, conifery, and sinapyl (Liu et al. 2018; Ganewatta et al. 2019).

Due to its complex and heterogeneous composition and structure, natural lignin is one of the most recalcitrant biopolymers (Bugg et al. 2011; Ganewatta et al. 2019). However, it does not accumulate in nature. After plant death, natural lignin undergoes natural biodegradation by soil microorganisms, which results in the formation of soil organic matter. Remarkable ligninolytic activity has been reported from a number of microorganisms. Studies on lignin biodegradation have focused primarily on basidiomycetous fungi (white rot and brown rot) since the mid-1980s. However, no commercial biocatalytic process for lignin depolymerization could be 
developed so far by using fungal isolates, which can be attributed to the difficulties associated with fungal genetic manipulation and fungal protein expression (Bugg et al. 2011). Ligninolytic bacteria have numerous advantages over fungi for biotechnological applications, such as rapid growth, easy genetic manipulation due to the small genome size, high stability and resilience in varying environmental conditions, and a great flexibility in the metabolism of lignin-related aromatic compounds (Bugg et al. 2011; Wang et al. 2018; Brink et al. 2019). Culturable lignin-degrading bacteria belong mostly to the phyla Actinobacteria, Firmicutes, and Proteobacteria. The classes Alpha and Gammaproteobacteria dominate among Proteobacteria (Bugg et al. 2011; Tian et al. 2014; Brink et al. 2019), while reports on the utilization of lignin by Betaproteobacteria are limited (Morya et al. 2019).

Currently, technical lignin is produced worldwide in high amounts in the pulp and paper industry and mainly used as an energy source to generate process steam and electricity. Technical lignin is also used in new biorefinery concepts, including 2nd-generation ethanol, and represents a major renewable source of aromatic and phenolic bio-products, which would be valuable raw materials for the synthesis of fine chemicals and materials and for the food and flavor industry (Bugg et al. 2011; Palazzolo and Kurina-Sanz 2016). In this context, there has been growing interest in the use of ferulic acid (FA) as feedstock for biocatalytic conversion into other value-added products, such as vanillin and vanillic acid (VA) (Rosazza et al. 1995). The study of ligninolytic microorganisms and the assessment of their potential is essential for lignin valorization (Ravi et al. 2018). More studies are needed to expand our knowledge on lignin monomer degradation (Wang et al. 2018).

Studies on lignin-degrading microorganisms have been performed under mesophilic conditions; however, ligninolytic activity under low-temperature conditions has not yet been studied. Cold-adapted microorganisms play a key ecological role in their natural habitats for nutrient cycling, litter degradation, and many other processes (Margesin and Collins 2019). Low-temperature biodegradation of a broad range of organic compounds, including alkanes and aromatic and polyaromatic hydrocarbons, has been reported in a number of studies (e.g., Bej et al. 2010; Margesin et al. 2013). Although low temperature results in a lower conversion rate, microbial activity under cold conditions offers a number of advantages for biotechnological processes and is of particular interest for low-energy treatments (Collins and Margesin 2019), e.g., for bioremediation in cold conditions. Furthermore, understanding lignin degradation in lowtemperature areas is of high ecological importance.

In an earlier study (Berger et al. 2021), we demonstrated the ability of a high number of bacterial strains isolated from soil from an Alpine coniferous forest site to utilize both watersoluble (leaf-soluble sugar (LSS)) and water-insoluble (lignin alkali) forms of lignin as sole carbon source. Among these strains, Paraburkholderia aromaticivorans AR20-38 was characterized by its ability to utilize high amounts of LSS and phenol as sole carbon source over its whole growth temperature range on these compounds $\left(0-30^{\circ} \mathrm{C}\right)$ and was therefore selected for further studies on lignin monomer degradation. It was the aim of this study to assess the ability of $P$. aromaticivorans AR20-38 (a member of Betaproteobacteria) to degrade six representative lignin monomers (syringic acid, p-coumaric acid, 4hydroxybenzoic acid, ferulic acid, vanillic acid, benzoic acid) that represent different branches of the upper funneling catabolic pathways for the bacterial metabolism of lignin components (sinapyl, p-coumaryl, coniferyl, benzoyl; Brink et al. 2019). Biodegradation studies were performed over a broad temperature range $\left(10-30^{\circ} \mathrm{C}\right)$. Special attention was paid to the bioconversion of FA to VA, and the sequenced draft genome (Poyntner et al. 2020) was analyzed for the presence of known genes being essential for the upper funneling aromatic pathways. Here, we report for the first time the degradation potential for lignin model compounds and the stable production of VA from FA under low-temperature conditions.

\section{Materials and methods}

\section{Strain}

The bacterial strain used in this study was isolated from soil from an Alpine coniferous forest site located $7 \mathrm{~km}$ north of Bozen/Bolzano, Italy, below the Rittner Horn at an altitude of 1724-1737 $\mathrm{m}$ above sea level as described (França et al. 2016) and identified as member of the species $P$. aromaticivorans (GenBank accession no. MT281269; Berger et al. 2021). The whole genome was sequenced, and the resulting draft genome sequence of the strain has been recently described (Poyntner et al. 2020) (GenBank BioProject number PRJNA624061). The strain was deposited in the China General Microbiological Culture Collection center under the number CGMCC 1.18749 and is publicly available. The strain was stored at $-80^{\circ} \mathrm{C}$ using ROTI@Store cryovials.

\section{Chemicals}

Syringic acid (SA; Alfa Aesar 5003), p-coumaric acid (CA; Sigma C9008), 4-hydroxybenzoic acid (HBA; Serva 25271), trans-ferulic acid (FA; Sigma-Aldrich 128708), vanillic acid (VA; Merck 841025), and benzoic acid (BA; Sigma-Aldrich 242381) were of chromatographic pure grade. Stock solutions $(0.5 \mathrm{M})$ were prepared in DMSO and stored at $4{ }^{\circ} \mathrm{C}$. Preliminary studies showed that the amount of DMSO added to the cultivation flasks by the addition of these compounds did not affect bacterial growth. 


\section{Biodegradation of lignin monomers (model compounds)}

The biodegradation assays were carried out in 100-ml Erlenmeyer flasks with screw caps containing $20 \mathrm{ml}$ of mineral salts medium (MM) supplemented with $5 \mathrm{mM}$ (final concentration) of one of the target compounds (SA, CA, HBA, FA, VA, BA) as sole carbon source. To ensure sufficient aeration, the culture flasks were opened regularly for sampling under sterile conditions. The biodegradation of FA was also evaluated with a final concentration of $10 \mathrm{mM} \mathrm{FA}$, using a $1 \mathrm{M}$ stock solution. The $\mathrm{pH}$-neutral MM contained (compositions indicated per liter) $\mathrm{Na}_{2} \mathrm{HPO}_{4} \times 2 \mathrm{H}_{2} \mathrm{O}(3.5 \mathrm{~g}), \mathrm{KH}_{2} \mathrm{PO}_{4}(2$ $\mathrm{g}),\left(\mathrm{NH}_{4}\right)_{2} \mathrm{SO}_{4}(1 \mathrm{~g}), \mathrm{MgSO}_{4} \times 7 \mathrm{H}_{2} \mathrm{O}(0.2 \mathrm{~g}), \mathrm{Ca}\left(\mathrm{NO}_{3}\right)_{2}$ x 4 $\mathrm{H}_{2} \mathrm{O}(0.05 \mathrm{~g})$, ammonium iron(III) citrate (10 $\left.\mathrm{mg}\right)$, a trace element, and a vitamin solution (Schlegel 1992; Margesin and Schinner 1997). The $\mathrm{pH}$ of the medium was adjusted to 7.0 after the addition of the compounds. For inoculation, a preculture prepared in MM containing glucose $\left(2 \mathrm{~g} \mathrm{l}^{-1}\right)$ as carbon source was prepared. The bacterial cells were separated by centrifugation (10,000 $\mathrm{x}$ g for $10 \mathrm{~min}$ ), washed twice with sterile MM, and suspended in MM. The initial (t0) optical density at $600 \mathrm{~nm}$ (OD600) in the inoculated flasks was adjusted to 0.05 . Two negative controls contained (1) sterile medium supplemented with lignin monomers and (2) inoculated medium without the target compounds. The flasks were incubated in triplicate at $10^{\circ} \mathrm{C}, 20^{\circ} \mathrm{C}$, and $30^{\circ} \mathrm{C}$ and $150 \mathrm{rpm}$. Growth (OD600), $\mathrm{pH}$ of the cultures, and the concentration of the lignin monomers were monitored in samples collected at regular time intervals.

\section{HPLC analysis}

Lignin monomers were quantified by using HPLC analysis. The samples for the analysis were centrifuged for $10 \mathrm{~min}$ at $20,000 \times \mathrm{g}$ to remove all larger particles. The supernatants were frozen at $-20^{\circ} \mathrm{C}$ before HPLC analysis. At least 0.7 $\mathrm{mL}$ of the supernatant was filtered through a $0.2-\mu \mathrm{m}$ RC filter. The analysis was performed on a Shimadzu Prominence system via a RFQ Fast Acid column $(50 \times 7.8 \mathrm{~mm}$, Phenomenex, Germany) at $70^{\circ} \mathrm{C}$. A time program starting with a flow rate of $0.25 \mathrm{ml} \mathrm{min}^{-1}$ for $20 \mathrm{~min}$, then ramping to $1.0 \mathrm{ml} \mathrm{min}^{-1}$ within $10 \mathrm{~min}$, and finally keeping this flow rate until method stop was used with $5 \mathrm{mM}$ sulfuric acid as the mobile phase. The separated components were measured via a UV detector at $220 \mathrm{~nm}$ and crosschecked at $270 \mathrm{~nm}$. As external standards, SA, CA, HBA, FA, VA, and BA were injected in concentrations of 1,5 , and $10 \mathrm{mM}$ to obtain a calibration curve.

\section{Genome analysis}

The draft genome of $P$. aromaticivorans AR20-38 (Poyntner et al. 2020) was analyzed for the presence of genes involved in upper lignin funneling pathways according to the eLignin Microbial Database (www.elignindatabase.com; Ravi et al. 2018; Brink et al. 2019) and genomes of comparable strains (Lee et al. 2019; Morya et al. 2019). Genes coding for essential enzymes in the bacterial lignin metabolism were identified in the annotated genome through the databases SwissProt (Bairoch and Apweiler 2000), COG (Galperin et al. 2015), TCDB (Saier et al. 2014), GO (Ashburner et al. 2000; The Gene Ontology Consortium 2019), PHI (Winnenburg et al. 2008; Urban et al. 2020), VFDB (Chen et al. 2012), CARD (Alcock et al. 2020), Effective T3 (Arnold et al. 2009), CAZy (Cantarel et al. 2009) RefSeq Non-Redundant Protein Database (O'Leary et al. 2016), and Pfam (El-Gebali et al. 2019).

\section{Results}

\section{Biodegradation of lignin monomers}

No abiotic losses of lignin monomers were detected at any of the incubation temperatures over the whole incubation periods (data not shown). The difference between the initial and the residual concentration of lignin monomers could thus be attributed to biodegradation. The initial $\mathrm{pH}$ of 7.0 in the culture media was not affected during growth and biodegradation.

Strain P. aromaticivorans AR20-38 was able to utilize four out of the six tested lignin monomers (CA, HBA, FA, BA) as sole carbon and energy source at all three test temperatures $\left(10,20\right.$, and $\left.30^{\circ} \mathrm{C}\right)$. SA and VA could not be utilized at any of the temperatures tested.

An increase in temperature resulted in accelerated growth and degradation (Fig. 1). At a cultivation temperature of $10^{\circ} \mathrm{C}$, $5 \mathrm{mM} \mathrm{HBA}$ and BA were fully degraded after 3 days, while 6 and 9 days were needed for the full degradation of $5 \mathrm{mM} \mathrm{CA}$ and $\mathrm{FA}$, respectively. At $20^{\circ} \mathrm{C}$, the four compounds were undetectable after 1 (HBA, BA), 2 (CA), and 6 (FA) days, respectively. At $30^{\circ} \mathrm{C}, \mathrm{CA}, \mathrm{HBA}$, and $\mathrm{BA}$ were consumed after 1 day, while 6 days were needed for FA. The degradation of FA was accompanied with the stable accumulation of VA due to bioconversion. Independent of the FA concentration or the incubation temperature, the maximum of VA was released when FA was fully degraded (see also below, Fig. 2).

The substrate preference among the lignin model compounds tested in this study was clearly visible at $10^{\circ} \mathrm{C}$ (HBA $\geq \mathrm{BA}>\mathrm{CA}>\mathrm{FA}$ ); at higher temperatures, no distinction between the degradation performance of $\mathrm{HBA}$ and $\mathrm{BA}$ $\left(20^{\circ} \mathrm{C}\right)$ or $\mathrm{HBA}, \mathrm{BA}$, and $\mathrm{CA}\left(30^{\circ} \mathrm{C}\right)$ was detectable.

The degradation of the lignin monomers paralleled growth (OD600); growth declined as soon as the carbon source was depleted (as also observed by Ravi et al. 2017). OD600 values, however, were not indicative of the degradation capacity. Biomass production was significantly higher during the degradation of CA $(\mathrm{OD} 600=1.3-1.4), \mathrm{BA}(\mathrm{OD} 600=$ 
Fig. 1 Effect of temperature on growth (left panels) and biodegradation (right panels) of lignin model compounds (CA, pcoumaric acid; HBA, 4-

hydroxybenzoic acid; FA, transferulic acid; BA, benzoic acid) as sole carbon source by

Paraburkholderia

aromaticivorans AR20-38 (mean values of three replicates; SDs were $\leq 10 \%$ ). VA production during FA consumption is not shown (see Fig. 2). The effect of temperature on growth with glucose as sole carbon source is shown in the left panel on the bottom
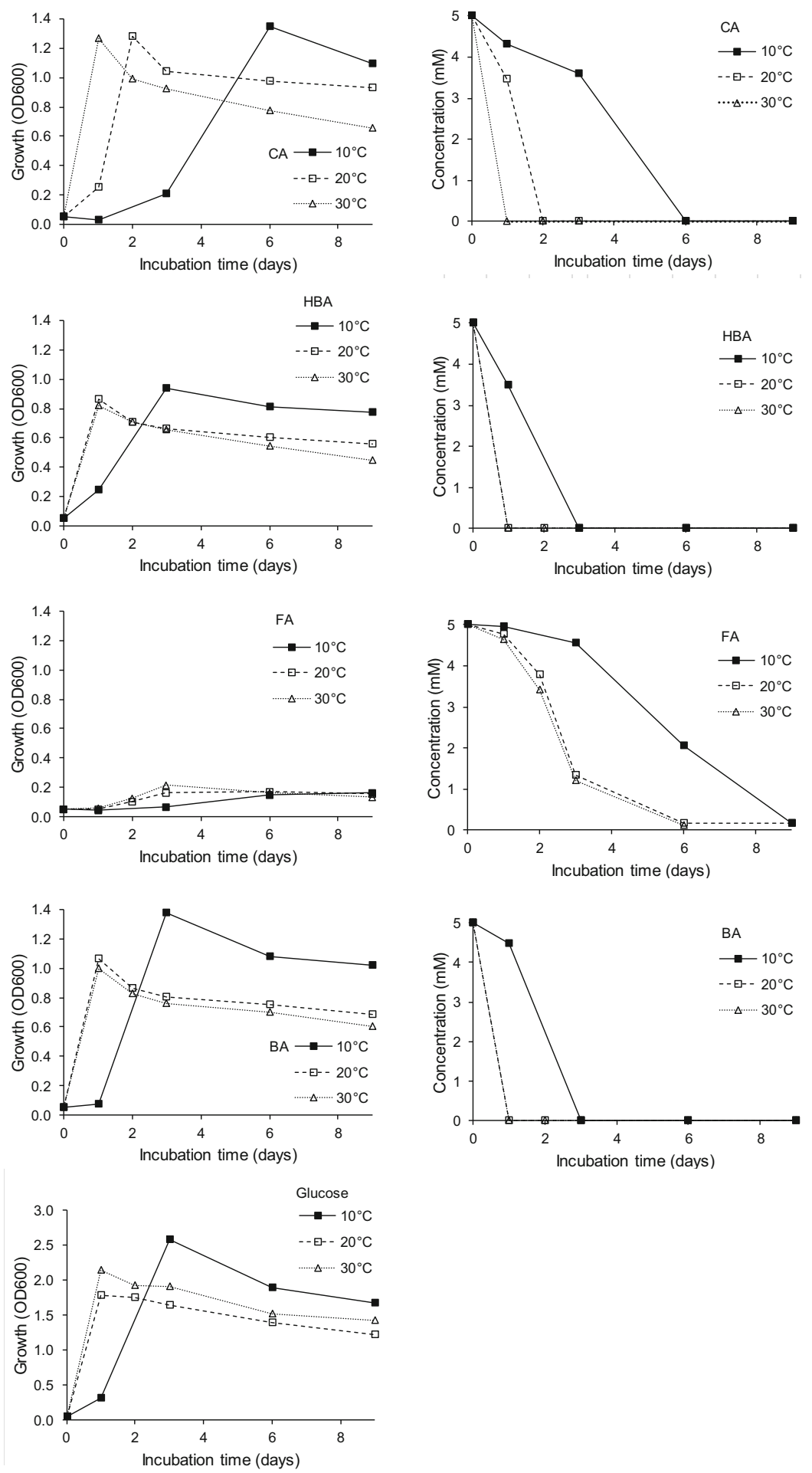

1-1.4), and HBA (OD600 $=0.8-0.9)$ (Fig. 1) than during FA degradation $(\mathrm{OD} 600=0.2)$ (Fig. 2). This occurred independent of the incubation temperature.

In all cases, growth at $10^{\circ} \mathrm{C}$ was delayed compared to growth at $20^{\circ} \mathrm{C}$ and $30^{\circ} \mathrm{C}$; however, it resulted in significantly higher biomass production in case of BA and glucose as sole carbon source. A tendency of increased biomass production at $10^{\circ} \mathrm{C}$, although not significant, was also visible for the other compounds consumed by the strain. Growth with glucose as the sole carbon source resulted in higher biomass production $(\mathrm{OD} 600=1.8-2.6)$ compared to growth with lignin monomers (Fig. 1). 
Fig. 2 Effect of temperature $\left(10^{\circ} \mathrm{C}, 20^{\circ} \mathrm{C}, 30^{\circ} \mathrm{C}\right)$ and $\mathrm{FA}$ concentration (left panels: $5 \mathrm{mM}$; right panels: $10 \mathrm{mM}$ ) on growth (upper panels) and bioconversion of FA (bottom panels) by Paraburkholderia

aromaticivorans AR20-38 (mean values of three replicates; SDs were $<5 \%$ )
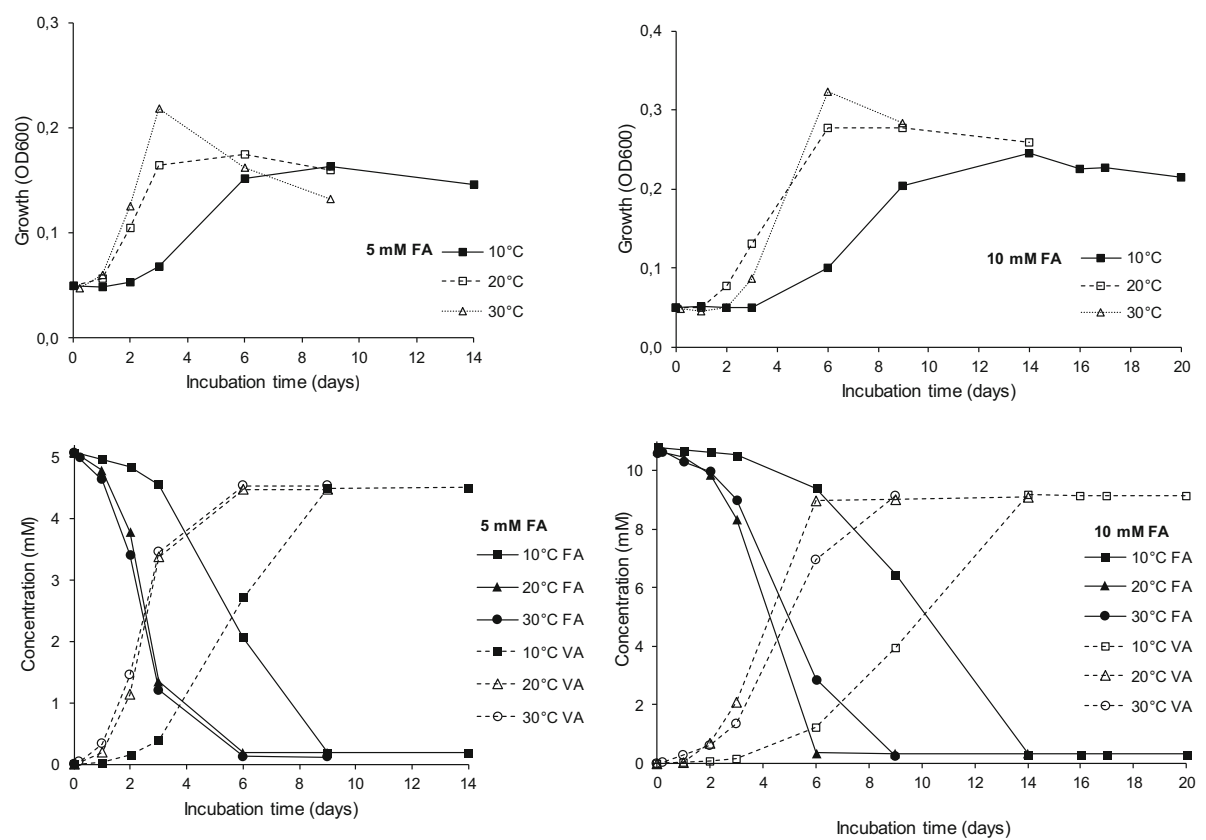

\section{Bioconversion of trans-ferulic acid to vanillic acid}

The degradation of FA was accompanied by the production of VA. This bioconversion occurred independently of the initial concentration of FA $(5 \mathrm{mM}, 10 \mathrm{mM})$ or the incubation temperature $\left(10,20,30^{\circ} \mathrm{C}\right)$ (Fig. 2). When FA was provided as sole carbon source, almost $75 \%$ of the initial concentration of $5 \mathrm{mM}$ FA were degraded after 3 days at 20 and $30^{\circ} \mathrm{C}$ (not detectable after 6 days), while still $40 \%$ were found after 6 days at $10^{\circ} \mathrm{C}$ (no detection after 9 days). An increase in the initial FA concentration $(10 \mathrm{mM})$ resulted in faster degradation at $20^{\circ} \mathrm{C}$ than at $30^{\circ} \mathrm{C}$ (not detectable after 6 and 9 days, respectively) or $10^{\circ} \mathrm{C}$ (not detectable after 14 days). Thus, a delay of the period needed for full degradation was only detected at $10^{\circ} \mathrm{C}$ and $30^{\circ} \mathrm{C}$, however, not at $20^{\circ} \mathrm{C}$. This points to a temperature of $20^{\circ} \mathrm{C}$ as the optimum temperature in terms of the degradation of high amounts of FA.

Using $5 \mathrm{mM}\left(1.022 \mathrm{~g} \mathrm{l}^{-1}\right) \mathrm{FA}$ as the sole source or carbon and energy, a maximum amount of $0.76 \mathrm{mg} \mathrm{VA}^{-1}$ (molar yield 88-89\%) was obtained in the medium at all three incubation temperatures. When the target concentration of $10 \mathrm{mM}$ FA $(10.6-10.8 \mathrm{mM})$ was provided, the molar yield $(85-86 \%$; $1.5 \mathrm{~g} \mathrm{l}^{-1}$ ) was only slightly lower (Table 1 ).

\section{Genome analysis}

The analysis of the three chromosomes and plasmid of the draft genome of $P$. aromaticivorans AR20-38 (Poyntner et al. 2020) revealed the presence of various genes involved in the degradation of the studied lignin model compounds (see Table 2 for details and loci). All genes related to lignin degradation were found in the core genome on chromosome 1,2 , and 3 .

Regarding CA degradation, genome analysis showed the presence of the gene encoding for enoyl-CA hydratase/lyase, which according to the suggested upper funneling aromatic pathway leads to the production of 4-hydroxybenzaldehyde (eLignin database). Genes related to enzymes involved in 4hydroxybenzaldehye consumption and thus HBA production were not present. The degradation of HBA, however, was confirmed by the presence of four genes encoding for 4hydroxybenzoate 3-monooxygenase, which results in the formation of protocatechuate.

FA degradation resulted in the synthesis and stable accumulation of VA. The transient production of the intermediate vanillin during FA bioconversion was evidenced by the presence of two genes encoding for the enzyme involved in the vanillin production from FA (feruloyl-CoA synthase). Genes for the enzyme involved in feruloyl-CA degradation (trans-feruloyl-CoA hydratase) were not found. The degradation of vanillin to VA was evidenced by the presence of a gene encoding for vanillin dehydrogenase (vanillin I funneling pathway; eLignin database). The stability of this product was confirmed by the inability of the strain to utilize VA as sole carbon source and by the absence of the gene for vanillate monooxygenase, which would produce protocatechuate from VA (vanillate monooxygenase). The presence of vanillate-O-demethylate oxidoreductase indicates the ability for the degradation of VA to catecholic structures, protocatechuate, and gallate (Kamimura et al. 2017), which is in contrast to the biodegradation results. 
Table 1 Effect of temperature $\left(10^{\circ} \mathrm{C}, 20^{\circ} \mathrm{C}, 30^{\circ} \mathrm{C}\right)$ on VA production from $5 \mathrm{mM}$ and $10 \mathrm{mM}$ FA obtained with Paraburkholderia aromaticivorans AR20-38 (mean values of three replicates \pm SD)

\begin{tabular}{|c|c|c|c|c|c|c|c|}
\hline \multirow[t]{2}{*}{ Temperature } & \multicolumn{2}{|c|}{ FA concentration (t0) } & \multicolumn{5}{|c|}{ VA production } \\
\hline & $\mathrm{mM}$ & $\operatorname{mg} 1^{-1}$ & $\mathrm{mM}$ & $\mathrm{mg}^{-1}$ & $\mathrm{~g}(1 \mathrm{x} \text { OD600 })^{-1}$ & Molar yield (\%) & Mass yield (\%) \\
\hline $10^{\circ} \mathrm{C}$ & $5.1 \pm 0.15$ & $984 \pm 29$ & $4.5 \pm 0.02$ & $757 \pm 3$ & $4.6 \pm 0.02$ & $88.9 \pm 2.42$ & $77.0 \pm 2.10$ \\
\hline $20^{\circ} \mathrm{C}$ & $5.1 \pm 0.15$ & $984 \pm 29$ & $4.5 \pm 0.02$ & $752 \pm 4$ & $4.3 \pm 0.02$ & $88.3 \pm 2.46$ & $76.5 \pm 2.13$ \\
\hline $30^{\circ} \mathrm{C}$ & $5.1 \pm 0.15$ & $984 \pm 29$ & $4.5 \pm 0.03$ & $760 \pm 4$ & $3.5 \pm 0.02$ & $89.3 \pm 2.44$ & $77.3 \pm 2.11$ \\
\hline $10^{\circ} \mathrm{C}$ & $10.8 \pm 0.04$ & $2098 \pm 8$ & $9.2 \pm 0.03$ & $1541 \pm 5$ & $6.3 \pm 0.02$ & $84.8 \pm 0.39$ & $73.4 \pm 0.33$ \\
\hline $20^{\circ} \mathrm{C}$ & $10.7 \pm 0.17$ & $2076 \pm 32$ & $9.1 \pm 0.04$ & $1531 \pm 7$ & $5.5 \pm 0.02$ & $85.1 \pm 0.95$ & $73.7 \pm 0.82$ \\
\hline $30^{\circ} \mathrm{C}$ & $10.6 \pm 0.23$ & $2063 \pm 44$ & $9.1 \pm 0.01$ & $1537 \pm 2$ & $4.8 \pm 0.01$ & $86.1 \pm 1.76$ & $74.6 \pm 1.53$ \\
\hline
\end{tabular}

Syringate O-demethylase, an enzyme responsible for SA degradation to 3-O-methylgallate and 5-methyltetrahydrofolate, was not present in the annotated genome data. In contrast, the enzymes benzoate 1,2-dioxygenase and 1,6dihydroxycyclohexa-2,4-diene-1-carboxylate-dehydrogenase, essential for BA degradation and leading to 3,5cyclohexadiene-1,2-diol-1-carboxylate and further to catechol, were present in the genome.

Catechol-1,2-dioxygenase can degrade catechol and is encoded in the annotated genome. It leads to the production of cis,cis-muconic acid. Further, genes for catechol 2,3dioxygenase were identified, an enzyme known to lead from catechol to $(2 \mathrm{Z}, 4 \mathrm{E})$-2-hydroxy-6-oxohexa-2,4-dienoate. The ability of $P$. aromaticivorans AR20-38 to utilize catechol is evidenced by its ability to utilize catechol as carbon source and to produce the relevant enzyme (Berger et al. 2021). Three additional genes present in the genome are potentially involved in the lignin degradation pathway: enoyl-CoA hydratase/isomerase in the vanillin funneling pathway (Gasson et al. 1998), benzaldehyde dehydrogenase in the syringyl lignin catabolism (Kamimura et al. 2017), and benzoyl-CoA oxygenase/reductase in assisting the breakdown of lignin (Kumar et al. 2018).

In the annotated gene, 980 genes related to transporters were identified (Table 3). In relation to lignin biodegradation, $\mathrm{ABC}$ transporters (e.g., vanillin transport), MFS transporters, and RND transporters (Morya et al. 2019) were present. Interestingly, genes encoding the MFS hydroxybenzoate transporters were found 19 times and on all chromosomes.

In the genome, various genes encoding transcriptional regulators (Table 3) are encoded. Similar to Burkholderia sp. ISTR5 (Morya et al. 2019), genes belonging to the LysR family were found, known for orthocleavage pathway of catechol. Further genes belonging to GntR, IclR, XRE, and MarR were found, which are known to be involved in hydrocarbon degradation (Morya et al. 2019, Tropel and van der Meer 2004).

\section{Discussion}

In this study, we report the degradation of the four lignin model compounds CA, HBA, FA, and BA and the bioconversion of FA to VA (with stable VA accumulation) over a wide temperature range, including cold conditions $\left(10-30^{\circ} \mathrm{C}\right)$, by the bacterial strain $P$. aromaticivorans AR20-38 isolated from soil from an Alpine coniferous forest site. The ability of bacterial strains isolated from this site to utilize lignin as sole carbon source has been reported previously (Berger et al. 2021). Members of the genus Paraburkholderia (order Burkholderiales, class Betaproteobacteria) have been isolated from diverse ecological niches. The majority originates from soils or in association with plant roots (Lee and Jeon 2018; Wilhelm et al. 2020). They are frequently isolated from forest soils (Xiao et al. 2019; Paulitsch et al. 2020; Wilhelm et al. 2020) where they are involved in the decomposition of plantderived aromatics and appear to play a role as principle contributors to the soil priming effect (Wilhelm et al. 2020). Genome analyses revealed the versatile metabolic capabilities of Paraburkholderia representatives, including a member of the species $P$. aromaticivorans, (Lee et al. 2019), for the degradation of organic compounds (Wilhelm et al. 2020 and references therein). Paraburkholderia members have been described as degraders of crude oil and aliphatic (n-hexadecane), monoaromatic (benzene; toluene; ethylbenzene; o-, m-, and pxylene; 4-hydroxybenzoic acid; halogenated phenols), and polycyclic aromatic (naphthalene, phenanthrene) hydrocarbons (Coenye et al. 2004; Li et al. 2017; Yuan et al. 2018; Lee et al. 2019; Wilhelm et al. 2020). However, to the best of our knowledge, no study has previously described the ligninolytic capacity of members of the genus Paraburkholderia (1) for biodegradation under lowtemperature conditions and (2) for the synthesis of VA from FA. Our study extends knowledge on the role of this genus in lignin utilization and on ligninolytic members of the class Betaproteobacteria, which have only rarely been described before (Tian et al. 2014; Brink et al. 2019; Morya et al. 2019). 


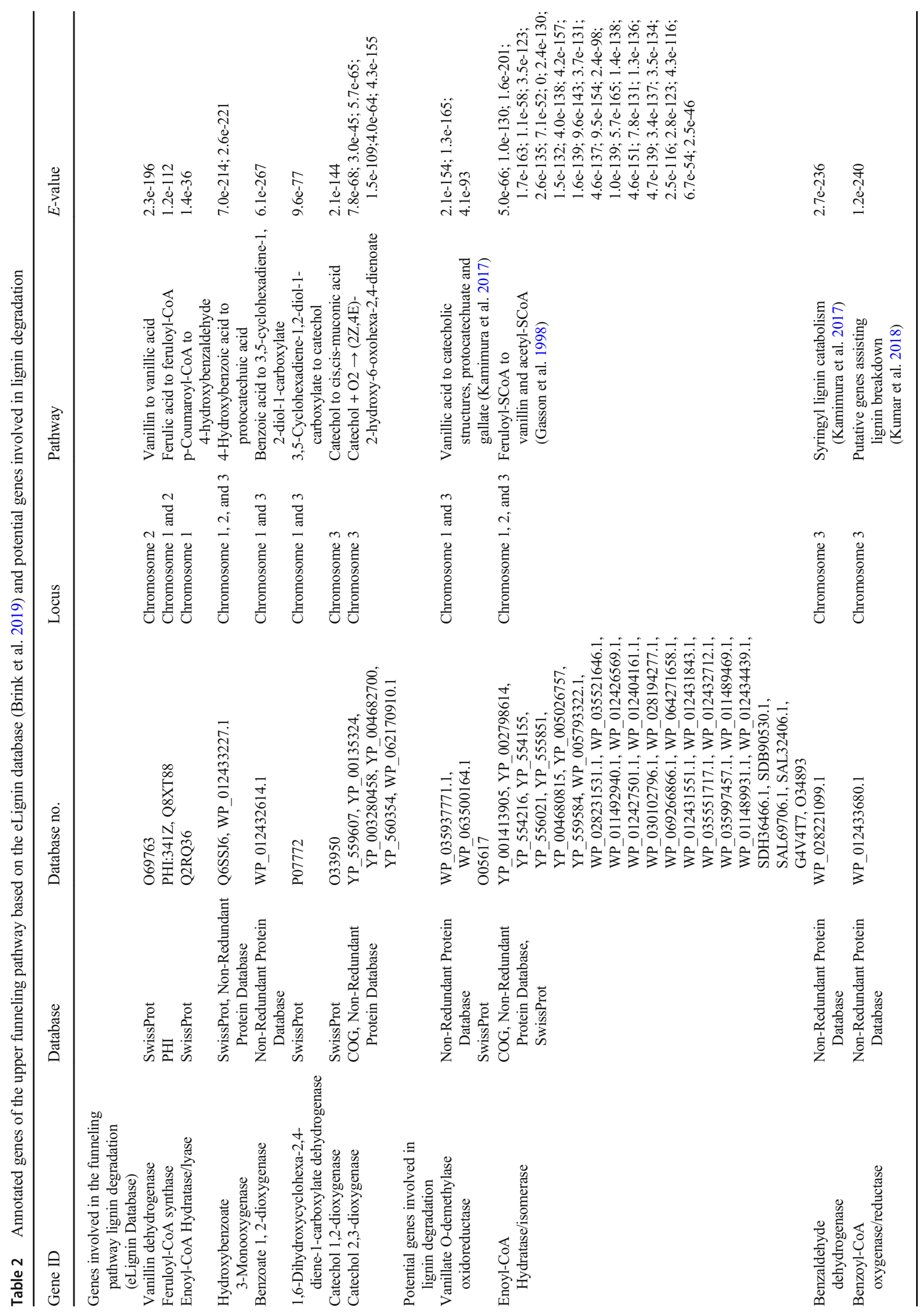


Table 3 Number of transporter and transcriptional regulator genes identified in the annotated genome

\begin{tabular}{ll}
\hline Transporter type & Number of annotated genes \\
\hline All & 980 \\
ABC transporter & 424 \\
MFS transporter & 205 \\
RND transporter & 11 \\
Transcriptional regulator & Number of annotated genes \\
Lys R & 232 \\
GntR & 110 \\
IclR & 121 \\
XRE & 48 \\
MarR & 122 \\
\hline
\end{tabular}

Our data show that $P$. aromaticivorans AR20-38 was unable to degrade lignin monomers of the sinapyl branch (SA); however, it was able to utilize three of the four main branches of the upper funneling catabolic pathways for the bacterial metabolism of lignin compounds: the p-coumaryl branch (CA and utilization of HA produced from CA), the coniferyl branch (FA, with accumulation of VA), and the benzoyl branch (BA). The preferential degradation of compounds of the p-coumaryl and benzoyl branches (detectable at $10^{\circ} \mathrm{C}$ ) compared to the coniferyl branch (at $10-30^{\circ} \mathrm{C}$ ) was clearly visible and is likely associated to the absence of a methyl group in these structures (BA, CA). Ravi et al. (2017) also observed that 4-hydroxybenzoate was preferentially consumed first, whereas ferulate was always the last consumed substrate by members of the genus Pseudomonas.

The genomic analysis supported the findings from biodegradation studies. For the degrading abilities of CA, HBA, FA, and BA, known genes are present in the draft genome. Genes of the upper funneling pathway are encoded in the core genome and are therefore essential for the strain. The genes for catechol degradation are only encoded on the same locus, chromosome 3 (Table 2), and might be regulated similarly, while other genes for the funneling pathway are distributed on two or all chromosomes. Genes encoding transcriptional regulators are found throughout the three chromosomes and are comparable to published (Para-)Burkolderia genomes (Lee et al. 2019; Morya et al. 2019). Known transcriptional factors for hydrocarbon degradation and catechol metabolism (e.g., LysR family) were identified. The high number of genes in the core genome encoding transporters (Table 3), e.g., ABC transporters, which can be involved in lignin derivative transport (Morya et al. 2019), supports the high biodegradation capability of the studied strain.

In this study, we also demonstrated the stable accumulation of the value-added product VA from FA by $P$. aromaticivorans AR20-38. Interestingly, genes for vanillate-O-demethylate oxidoreductase are present in the genome, which is used to degrade
VA to catecholic structures (Kamimura et al. 2017). The strain might down-regulate this gene under the studied conditions and therefore was not able to degrade VA. After complete degradation of FA, no more biomass is produced (Fig. 1). To understand the lack of further VA degradation, detailed experiments are planned. In the genome, several genes, e.g., benzaldehyde dehydrogenase (Table 2), are present, which are potentially involved in lignin biodegradation. Therefore, it would be interesting to study the transcriptome during degradation in future studies.

Moreover, the strain tolerated and converted high concentrations (10 mM) of FA without growth inhibition. A comparable FA tolerance has only been described with an engineered Pseudomonas putida strain (Upadhyay et al. 2019). In comparison, FA concentrations above $5 \mathrm{mM}$ had a growthinhibiting effect on Halomonas elongata (Abdelkafi et al. 2006) and reduced the VA production yield of Streptomyces sannanensis (Ghosh et al. 2007); Paenibacillus lactis showed a very low conversion yield in the presence of $5 \mathrm{mM}$ FA compared to $2.5 \mathrm{mM}$ FA (Mishra et al. 2016).

An important criterion for biotechnological application is the bioconversion yield. In our study, the molar yield of VA produced from $5 \mathrm{mM}$ FA was $88-89 \%$ and was marginally lower using 10 mM FA (85-86\%) (Table 1). Remarkably, this high yield from pure FA was obtained at $10^{\circ} \mathrm{C}, 20^{\circ} \mathrm{C}$, and $30^{\circ} \mathrm{C}$. A comparable bioconversion molar yield from $10 \mathrm{mM}$ FA has only been obtained with an engineered $P$. putida strain at $30^{\circ} \mathrm{C}$ (95\%; Upadhyay et al. 2019) and - from only $5 \mathrm{mM}$ FA - with $H$. elongata at $37^{\circ} \mathrm{C}(86 \%$; Abdelkafi et al. 2006) and Streptomyces halstedii at $28^{\circ} \mathrm{C}(80 \%$; Brunati et al. 2004). Other reported bioconversion molar yields are in the range of $60 \%$ (produced from $5 \mathrm{mM} \mathrm{FA}$ at $37^{\circ} \mathrm{C}$ by Bacillus licheniformis; Ashengroph et al. 2012), 38\% (2.5 mM FA, $37^{\circ} \mathrm{C}$, Paenibacillus; Mishra et al. 2016), or $11 \%$ (5 mM FA, $30^{\circ} \mathrm{C}$, Streptomyces setonii; Muheim and Lerch 1999).

When considering the quite low amount of biomass produced during FA bioconversion by the strain used in this study, the performance becomes even more remarkable. Further studies to optimize the carbon balance should allow the optimal balance between growth rate, low substrate metabolism into biomass, and VA production without slowing down the conversion rate. This could be obtained by studying (i) the optimal media composition as previously reported (Ghosh et al. 2006; Mishra et al. 2016), (ii) in vitro conversion of FA to VA with cell extracts, and (iii) by increasing the amount of the substrate FA.

The reported bioconversion ability of the strain $P$. aromaticivorans AR20-38 to produce VA from FA is interesting from the viewpoint of application. FA (3-(4-hydroxy-3methoxyphenyl)-2-propenoic acid) is very abundant in agricultural plants (by-products) as well as in softwood lignin and thus a natural renewable resource for the production of vanillin and VA (Ashengroph et al. 2012). There is a growing interest in exploiting microbial conversions of FA for the production of 
commercially valuable products, such as VA, vanillin, 4-vinyl guaiacol, and styrenes (Rosazza et al. 1995). VA (4-hydroxy-3methoxy benzoic acid) production is especially interesting as this compound is used as the starting material in the chemical synthesis of vanillin (Rosazza et al. 1995) as well as polyesters; it is a potential food preservative and has been associated with a range of pharmacologic activities (Abdelkafi et al. 2006, Ghosh et al. 2007; Gitzinger et al. 2012). Besides FA, related abundant lignin monomers, such as p-coumaric acid, are attractive aromatic compounds of great value as precursors for other useful chemical products (Rosazza et al. 1995).

Studies on the biodegradation of lignin monomers have been conducted under mesophilic temperature conditions, i.e., at temperatures ranging from 28 to $37^{\circ} \mathrm{C}$ (Abdelkafi et al. 2006; Ghosh et al. 2007; Mishra et al. 2016; Ravi et al. 2017; Upadhyay et al. 2019). Our study is the first to report the biodegradation of lignin monomers (CA, HBA, FA, BA) and the bioconversion of FA to VA at lower temperatures. The ability of the studied strain for low-temperature growth and degradation can be attributed to its isolation source, an Alpine soil in a subalpine-continental climate with a mean annual air and soil temperature of $4.0^{\circ} \mathrm{C}$ and $4.3^{\circ} \mathrm{C}$, respectively (França et al. 2016). The observed maintenance of a consistent degradation activity and a consistent conversion yield over a broad temperature range $\left(10-30^{\circ} \mathrm{C}\right)$ is of biotechnological interest and is advantageous in environments that undergo thermal fluctuations. Such strains are useful for low-energy treatment of lignin and temperature-independent valuable product formation. Microbial cold adaptation includes a complex range of structural and functional adaptations at the level of all cellular constituents and offers multiple biotechnological applications (De Maayer et al. 2014; Margesin 2017; Collins and Margesin 2019).

In conclusion, the data obtained in this study demonstrate that $P$. aromaticivorans AR20-38 is characterized by a number of interesting capacities: (1) full degradation of a range of lignin monomers (5 mM CA, $5 \mathrm{mM} \mathrm{HBA}$, $5 \mathrm{mM} \mathrm{BA}$, and 5-10 mM FA at $10-30^{\circ} \mathrm{C}$ ), (2) high bioconversion capacity for the stable production of $\mathrm{VA}$ from $\mathrm{FA}$ at $10-30^{\circ} \mathrm{C}: 88-89 \%$ (from $5 \mathrm{mM} \mathrm{FA}$ ) to $85-86 \%$ (from $10 \mathrm{mM}$ ) molar yield at $10-30^{\circ} \mathrm{C}$, and (3) tolerance to high amounts of FA without inhibition of growth and/or bioconversion. These features, obtained without further optimization, indicate the potential of the strain for biotechnological application. Its ability to utilize a number of other aromatic and polyaromatic hydrocarbons (phenol, catechol, naphthalene, phenanthrene) as sole carbon source (Berger et al. 2021) is an additional advantage. Moreover, biodegradation and bioconversion over a broad temperature range, including cold conditions, are of industrial relevance for low-energy treatments. Additional studies on gene expression would be of great interest to understand degradation mechanisms on a transcriptomic level.
Acknowledgements We thank Petra Thurnbichler for her skillful assistance.

Author contribution RM designed the study and the concept. GV performed the laboratory experiments, and AOW designed and performed the HPLC method. RM, GV, and AOW analyzed the experimental results. DZ contributed to the whole genome sequencing. CP analyzed the genome data. RM and CP wrote the manuscript. All authors read and approved the manuscript.

Funding Open access funding provided by University of Innsbruck and Medical University of Innsbruck.

Data Availability All data is presented in the manuscript, and the genome data can be found at the GenBank BioProject number PRJNA624061.

\section{Declarations}

Ethics approval This article does not contain any studies with human participants or animals performed by any of the authors.

Consent to participate Not applicable

Consent for publication All authors declared their consent for publication.

Conflict of interest The authors declare no conflict of interest.

Open Access This article is licensed under a Creative Commons Attribution 4.0 International License, which permits use, sharing, adaptation, distribution and reproduction in any medium or format, as long as you give appropriate credit to the original author(s) and the source, provide a link to the Creative Commons licence, and indicate if changes were made. The images or other third party material in this article are included in the article's Creative Commons licence, unless indicated otherwise in a credit line to the material. If material is not included in the article's Creative Commons licence and your intended use is not permitted by statutory regulation or exceeds the permitted use, you will need to obtain permission directly from the copyright holder. To view a copy of this licence, visit http://creativecommons.org/licenses/by/4.0/.

\section{References}

Abdelkafi S, Sayadi S, Ben Ali Gam Z, Casalot L, Labat M (2006) Bioconversion of ferulic acid to vanillic acid by Halomonas elongata isolated from table-olive fermentation. FEMS Microbiol Lett 262:115-120

Alcock BP, Raphenya AR, Lau TTY, Tsang KK, Bouchard M, Edalatmand A, Huynh W, Nguyen AV, Cheng AA, Liu S, Min SY, Miroshnichenko A, Tran HK, Werfalli RE, Nasir JA, Oloni M, Speicher DJ, Florescu A, Singh B, Faltyn M, HernandezKoutoucheva A, Sharma AN, Bordeleau E, Pawlowski AC, Zubyk HL, Dooley D, Griffiths E, Maguire F, Winsor GL, Beiko RG, Brinkman FSL, Hsiao WWL, Domselaar GV, McArthur AG (2020) CARD 2020: antibiotic resistome surveillance with the comprehensive antibiotic resistance database. Nucleic Acids Res 48: D517-D525. https://doi.org/10.1093/nar/gkz935

Arnold R, Brandmaier S, Kleine F, Tischler P, Heinz E, Behrens S, Niinikoski A, Mewes HW, Horn M, Rattei T (2009) Sequence- 
based prediction of type III secreted proteins. PLoS Pathog 5(4): e1000376. https://doi.org/10.1371/journal.ppat.1000376

Ashburner M, Ball CA, Blake JA, Botstein D, Butler H, Cherry JM, Davis AP, Dolinski K, Dwight SS, Eppig JT, Harris MA, Hill DP, Issel-Tarver L, Kasarskis A, Lewis S, Matese JC, Richardson JE, Ringwald M, Rubin GM, Sherlock G (2000) Gene Ontology: tool for the unification of biology. Nat Genet 25:25-29. https://doi.org/ $10.1038 / 75556$

Ashengroph M, Nahvi I, Zarkesh-Esfahani H, Momenbeik F (2012) Novel strain of Bacillus licheniformis SHL1 with potential converting ferulic acid into vanillic acid. Ann Microbiol 62:553558

Bairoch A, Apweiler R (2000) The SWISS-PROT protein sequence database and its supplement TrEMBL in 2000. Nucleic Acids Res 28: 45-48. https://doi.org/10.1093/nar/28.1.45

Becker J, Wittmann C (2019) A field of dreams: lignin valorization into chemicals, materials, fuels, and health-care products. Biotechnol Adv 37:107360. https://doi.org/10.1016/j.biotechadv.2019.02.016

Bej AK, Aislabie J, Atlas RM (eds) (2010) Polar microbiology. CRC Press, Boca Raton

Berger T, Poyntner C, Margesin R (2021) Culturable bacteria from an Alpine coniferous forest site: biodegradation potential of organic polymers and pollutants. Folia Microbiol 66:87-98. https://doi.org/ 10.1007/s12223-020-00825-1

Brink DP, Ravi K, Lidén G, Gorwa-Grausland MF (2019) Mapping the diversity of microbial lignin catabolism: experiences from the eLignin database. Appl Microbiol Biotechnol 103:3979-4002

Brunati M, Marinelli F, Bertolini C, Gandolfi R, Daffonchio D, Molinari F (2004) Biotransformations of cinnamic and ferulic acid with actinomycetes. Enzym Microb Technol 34:3-9

Bugg TDH, Ahmad M, Hardiman EM, Singh R (2011) The emerging role for bacteria in lignin degradation and bio-product formation. Curr Open Biotechnol 22:394-400

Cantarel BL, Coutinho PM, Rancurel C, Bernard T, Lombard V, Henrissat B (2009) The carbohydrate-active enZymes database (CAZy): an expert resource for glycogenomics. Nucleic Acids Res 37:D233-D238. https://doi.org/10.1093/nar/gkn663

Chen L, Xiong Z, Sun L, Yang J, Jin Q (2012) VFDB 2012 update: toward the genetic diversity and molecular evolution of bacterial virulence factors. Nucleic Acids Res 40:641-645. https://doi.org/ 10.1093/nar/gkr989

Coenye T, Henry D, Speert DP, Vandamme P (2004) Burkholderia phenoliruptrix sp. nov., to accommodate the 2,4,5trichlorophenoxyacetic acid and halophenol-degrading strain AC11100. Syst Appl Microbiol 27:623-627

Collins T, Margesin R (2019) Psychrophilic lifestyles: mechanisms of adaptation and biotechnological tools. Appl Microbiol Biotechnol 103:2857-2871. https://doi.org/10.1007/s00253-019-09659-C5

De Maayer P, Anderson D, Cary C, Cowan DA (2014) Some like it cold: understanding the survival strategies of psychrophiles. EMBO Rep 15:508-517

El-Gebali S, Mistry J, Bateman A, Eddy SR, Luciani A, Potter SC, Qureshi M, Richardson LJ, Salazar GA, Smart A, Sonnhammer ELL, Hirsh L, Paladin L, Piovesan D, Tosatto SCE, Finn RD (2019) The Pfam protein families database in 2019. Nucleic Acids Res 47:D427-D432. https://doi.org/10.1093/nar/gky995

França L, Sannino C, Turchetti B, Buzzini P, Margesin R (2016) Seasonal and altitudinal changes of culturable bacterial and yeast diversity in Alpine forest soils. Extremophiles 20:855-873. https://doi.org/10. 1007/s00792-016-0874-2

Galperin MY, Makarova KS, Wolf YI, Koonin EV (2015) Expanded microbial genome coverage and improved protein family annotation in the COG database. Nucleic Acids Res 43:D261-D269. https:// doi.org/10.1093/nar/gku1223
Ganewatta MS, Lokupitiya HN, Tang C (2019) Lignin biopolymers in the age of controlled polymerization. Polymers 11:1176. https://doi. org/10.3390/polym11071176

Gasson MJ, Kitamura Y, McLauchlan WR, Narbad A, Parr AJ, Parsons EL, Payne J, Rhodes MJ, Walton NJ (1998) Metabolism of ferulic acid to vanillin. A bacterial gene of the enoyl-SCoA hydratase/ isomerase superfamily encodes an enzyme for the hydration and cleavage of a hydroxycinnamic acid SCoA thioester. J Biol Chem 273(7):4163-4170. https://doi.org/10.1074/jbc.273.7.4163

Ghosh S, Sachan A, Mitra A (2006) Formation of vanillic acid from ferulic acid by Paecilomyces variotii MTCC 6581. Curr Sci 90: 825-829

Ghosh S, Sachan A, Sen SK, Mitra A (2007) Microbial transformation of ferulic acid to vanillic acid by Streptomyces sannanensis MTCC 6637. J Ind Microbiol Biotechnol 34:131-138

Gitzinger M, Kemmer C, Fluri DA, El-Baba MD, Weber W, Fussenegger M (2012) The food additive vanillic acid controls transgene expression in mammalian cells and mice. Nucleic Acids Res 40:e37

Kamimura N, Takahashi K, Mori K, Araki T, Fujita M, Higuchi Y, Masai E (2017) Bacterial catabolism of lignin-derived aromatics: new findings in a recent decade: Update on bacterial lignin catabolism. Environ Microbiol Rep 9:679-705. https://doi.org/10.1111/17582229

Kumar M, Verma S, Gazara RK, Kumar M, Pandey A, Verma PK, Thakur IS (2018) Genomic and proteomic analysis of lignin degrading and polyhydroxyalkanoate accumulating $\beta$ proteobacterium Pandoraea sp. ISTKB. Biotechnol Biofuels 11: 154. https://doi.org/10.1186/s13068-018-1148-2

Lee Y, Jeon CO (2018) Paraburkholderia aromaticivorans sp. nov., an aromatic hydrocarbon-degrading bacterium, isolated from gasolinecontaminated soil. Int J Syst Evol Microbiol 68:1251-1257

Lee Y, Lee Y, Jeon CO (2019) Biodegradation of naphthalene, BTEX, and aliphatic hydrocarbons by Paraburkholderia aromaticivorans BN5 isolated from petroleum-contaminated soil. Sci Rep 9:860

Li JB, Zhang DY, Song MK, Jiang LF, Wang YJ, Luo CL, Zhang G (2017) Novel bacteria capable of degrading phenanthrene in activated sludge reveled by stable-isotope probing coupled with highthroughput sequencing. Biodegradation 28:423-436

Liu Z, Liu Y, Zeng G, Shao B, Chen M, Li Z, Jiang Y, Liu Y, Zhang Y, Zhong H (2018) Applications of molecular docking for the degradation of organic pollutants in the environmental remediation: a review. Chemosphere 203:139-150

Ludmila H, Michal J, Andrea Š, Aleš H (2015) Lignin, potential products and their market value. Wood Res 60:973-986

Margesin R (ed) (2017) Psychrophiles: from biodiversity to biotechnology, 2nd edn. Berlin, Springer

Margesin R, Collins T (2019) Microbial ecology of the cryosphere (glacial and permafrost habitats): current knowledge. Appl Microbiol Biotechnol 103:2537-2549. https://doi.org/10.1007/s00253-01909631-3

Margesin R, Schinner F (1997) Bioremediation of diesel-oil contaminated alpine soils at low temperatures. Appl Microbiol Biotechnol 47: 462-468

Margesin R, Moertelmaier C, Mair J (2013) Low-temperature biodegradation of petroleum hydrocarbons (n-alkanes, phenol, anthracene, pyrene) by four actinobacterial strains. Int Biodeterior Biodegrad 84: 185-191

Mishra S, Kullu M, Sachan A, Vidyarthy AS, Ghosh Sachan S (2016) Bioconversion of ferulic acid to vanillic acid by Paenibacillus lactis SAMS-2001. Ann Microbiol 66:875-882

Morya R, Kumar M, Singh SS, Thakur IS (2019) Genomic analysis of Burkholderia sp. ISTR5 for biofunneling of lignin-derived compounds. Biotechnol Biofuels 12:277

Muheim A, Lerch K (1999) Towards a high-yield bioconversion of ferulic acid to vanillin. Appl Microbiol Biotechnol 51:456-461 
O'Leary NA, Wright MW, Brister JR, Ciufo S, Haddad D, McVeigh R, Rajput B, Robbertse B, Smith-White B, Ako-Adjei D, Astashyn A, Badretdin A, Bao Y, Blinkova O, Brover V, Chetvernin V, Choi J, Cox E, Ermolaeva O, Farrell CM, Goldfarb T, Gupta T, Haft D, Hatcher E, Hlavina W, Joardar VS, Kodali VK, Li W, Maglott D, Masterson P, McGarvey KM, Murphy MR, O'Neill K, Pujar S, Rangwala SH, Rausch D, Riddick LD, Schoch C, Shkeda A, Storz SS, Sun H, Thibaud-Nissen F, Tolstoy I, Tully RE, Vatsan AR, Wallin C, Webb D, Wu W, Landrum MJ, Kimchi A, Tatusova T, DiCuccio M, Kitts P, Murphy TD, Pruitt KD (2016) Reference sequence (RefSeq) database at NCBI: current status, taxonomic expansion, and functional annotation. Nucleic Acids Res 44D1:D733D745. https://doi.org/10.1093/nar/gkv1189

Palazzolo MA, Kurina-Sanz M (2016) Microbial utilization of lignin: available biotechnologies for its degradation and valorization. World J Microbiol Biotechnol 32:173

Paulitsch F, Fuzinatto Dall'Agnol R, Marçon Delamuta JR, Ribeiro RA, da Silva Batista JS, Hungria M (2020) Paraburkholderia atlantica sp. nov. and Paraburkholderia franconis sp. nov., two new nitrogen-fixing nodulating species isolated from Atlantic forest soils in Brazil. Arch Microbiol 202:1369-1380

Poyntner C, Zhang D, Margesin R (2020) Draft genome sequence of the bacterium Paraburkholderia aromaticivorans AR20-38, a Gramnegative, cold-adapted degrader of aromatic compounds. Microbiol Resour Announc 9e00463-20. https://doi.org/10.1128/ MRA.00463-20

Ravi K, Garcia-Hidalgo J, Gorwa-Grausland MF, Lidén G (2017) Conversion of lignin model compounds by Pseudomonas putida KT2440 and isolates from compost. Appl Microbiol Biotechnol 101:5059-5070

Ravi K, Garcia-Hidalgo J, Nöbel M, Gorwa-Grausland MF, Lidén G (2018) Biological conversion of aromatic monolignol compounds by a Pseudomonas isolate from sediments of the Baltic Sea. AMB Express 8:32

Rosazza JPN, Huang Z, Dolstal L, Volm T, Rousseau B (1995) Review: biocatalytic transformations of ferulic acid: an abundant aromatic natural product. J Ind Microbiol 15:457-471

Saier MH, Reddy VS, Tamang DG, Västermark A (2014) The transporter classification database. Nucleic Acids Res 42:251-258. https://doi. org/10.1093/nar/gkt1097

Schlegel HG (1992) Allgemeine Mikrobiologie, 7. Auflage edn. Georg Thieme Verlag, Stuttgart
The Gene Ontology Consortium (2019) The Gene Ontology resource: 20 years and still GOing strong. Nucleic Acids Res 47:D330-D338. https://doi.org/10.1093/nar/gky1055

Tian J-H, Pourcher A-M, Bouchez T, Gelhaye E, Peu P (2014) Occurrence of lignin degradation genotypes and phenotypes among prokaryotes. Appl Microbiol Biotechnol 98:9527-9544

Tropel D, van der Meer JR (2004) Bacterial transcriptional regulators for degradation pathways of aromatic compounds. Microbiol Mol Biol Rev 68(3):474-500. https://doi.org/10.1128/MMBR.68.3.474-500. 2004

Upadhyay P, Singh NK, Tupe R, Odenath A, Lali A (2019) Biotransformation of corn bran derived ferulic acid to vanillic acid using engineered Pseudomonas putida KT2440. Prep Biochem Biotechnol 50:341-348

Urban M, Cuzick A, Seager J, Wood V, Rutherford K, Venkatesh SJ, De Silva N, Carbajo Martinez M, Pedro H, Yates AD, Hassani-Pak K, Zammond-Kosack KE (2020) PHI-base: the pathogen-host interactions database. Nucleic Acids Res 48:D613-D620. https://doi.org/ 10.1093/nar/gkz904

Wang J, Liang J, Gao S (2018) Biodegradation of lignin monomers vanillic, $p$-coumaric, and syringic acid by the bacterial strain Sphingobacterium sp. HY-H. Curr Microbiol 75:1156-1164

Wilhelm RC, Murphy SJL, Feriancek NM, Karasz DC, DeRito CM, Newman JD, Buckley DH (2020) Paraburkholderia madseniana sp. nov., a phenolic acid-degrading bacterium isolated from acidic forest soil. Int J Syst Evol Microbiol 70:2137-2146

Winnenburg R, Urban M, Beacham A, Baldwin TK, Holland S, Lindeberg M, Hansen H, Rawlings C, Hammond-Kosack KE, Kohler J (2008) PHI-base update: additions to the pathogen host interaction database. Nucleic Acids Res 36:D572-D576

Xiao S-Y, Gao Z-H, Qiu L-H (2019) Paraburkholderia pallida sp. nov. and Paraburkholderia silviterrae sp. nov. isolated from forest soil. Int J Syst Evol Microbiol 69:3777-3785

Yuan XY, Zhang XY, Cen XP, Kong DW, Liu XY, Shen SY (2018) Synergistic degradation of crude oil by indigenous bacterial consortium and exogenous fungus Scedosporium boydii. Bioresour Technol 264:190-197

Publisher's note Springer Nature remains neutral with regard to jurisdictional claims in published maps and institutional affiliations. 